\title{
Flame retardancy behaviors of flexible polyurethane foam based on reactive dihydroxy $\mathrm{P}-\mathrm{N}$-containing flame retardant
}

\author{
Yulin Ding ${ }^{a, b}$, Yumiao Sub ${ }^{b, c}$, Jiajing Huang ${ }^{a, b}$, Ting Wang ${ }^{b, c}$, Min-Yu Li ${ }^{d}$, and Wenmu Li ${ }^{b, *}$ \\ ${ }^{a}$ Fujian Normal University, College of Chemistry and Material Science, Fuzhou, Fujian 350007, \\ China; \\ ${ }^{\boldsymbol{b}}$ Key Laboratory of Optoelectronic Materials Chemistry and Physics, Fujian Institute of Research \\ on the Structure of Matter, Chinese Academy of Sciences, Fuzhou 350002, China. \\ ${ }^{c}$ University of Chinese Academy of Sciences, Beijing 100049, China. \\ ${ }^{\boldsymbol{d}}$ College of Chemistry and Materials, Ningde Normal University, Ningde 352100, China.
}

E-mail:liwm@fjirsm.ac.cn 


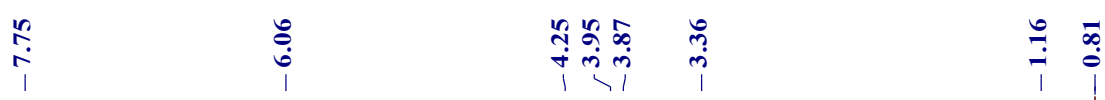
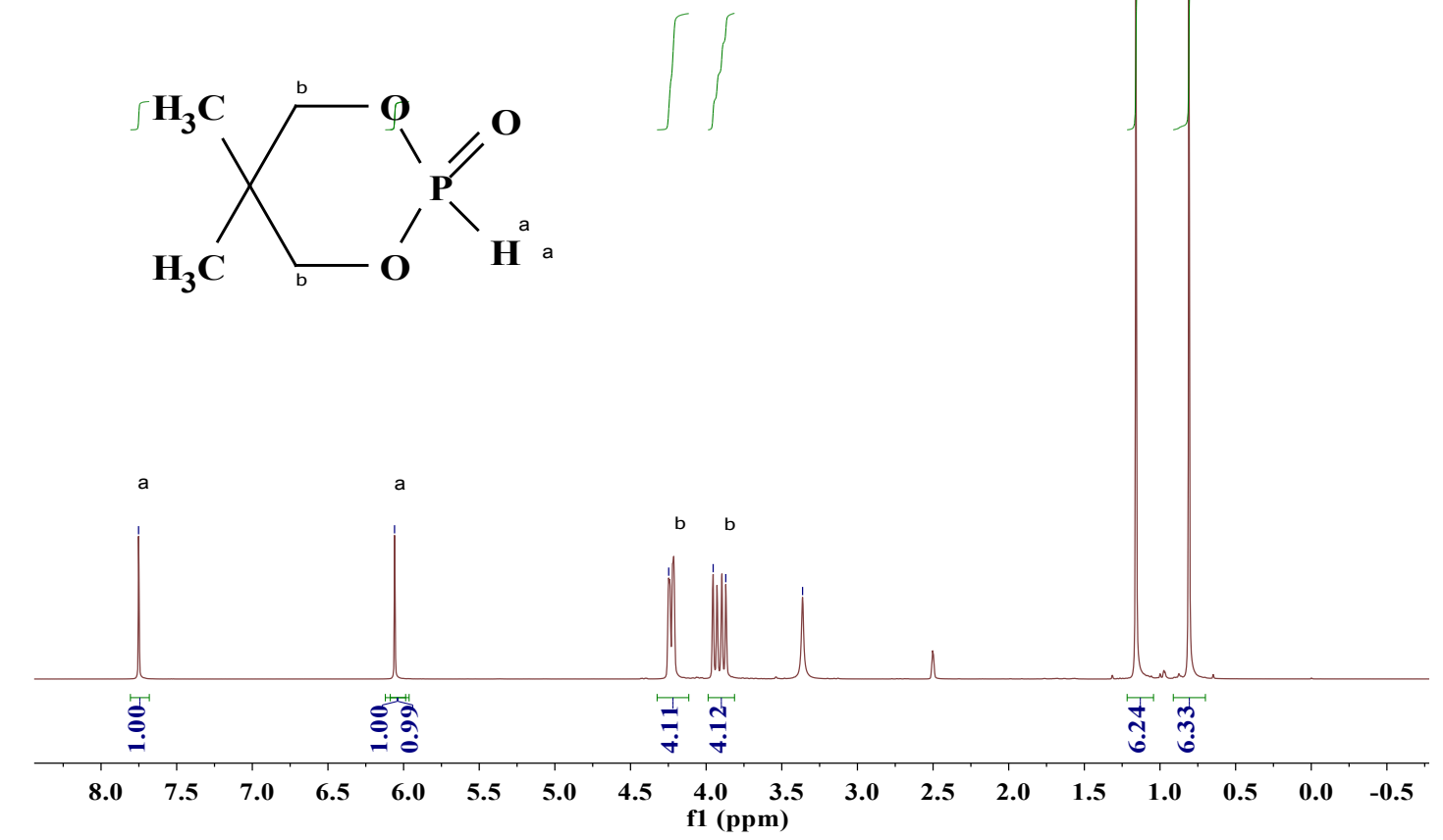

Figure S1. ${ }^{1} \mathrm{H}$ NMR spectra of DMPP $\left(d_{6}\right.$-DMSO $)$

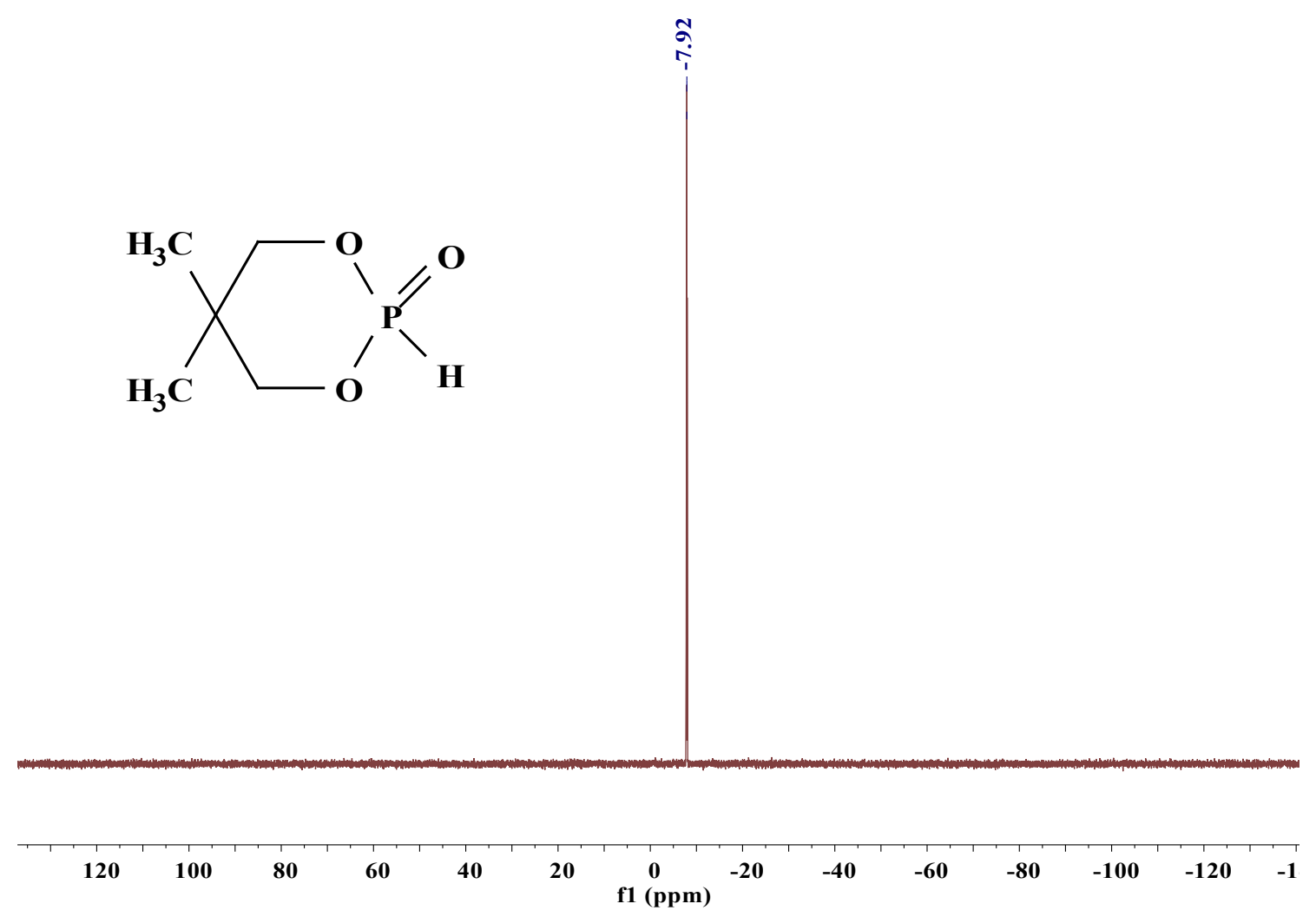

Figure S2. ${ }^{31} \mathrm{P}$ NMR spectra of DMPP ( $d_{6}$-DMSO) 


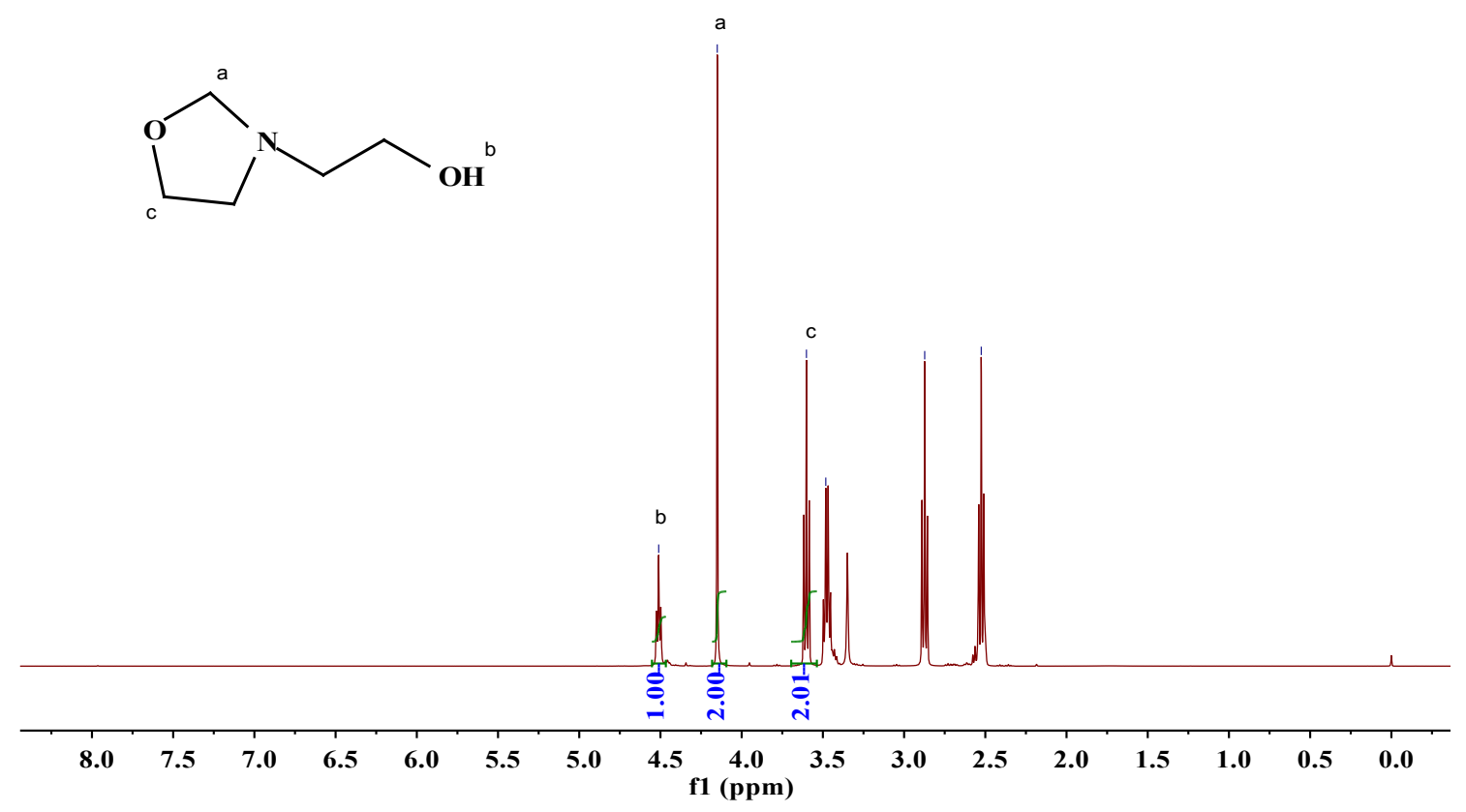

Figure S3. ${ }^{1} \mathrm{H}$ NMR spectra of HENH $\left(d_{6}\right.$-DMSO)
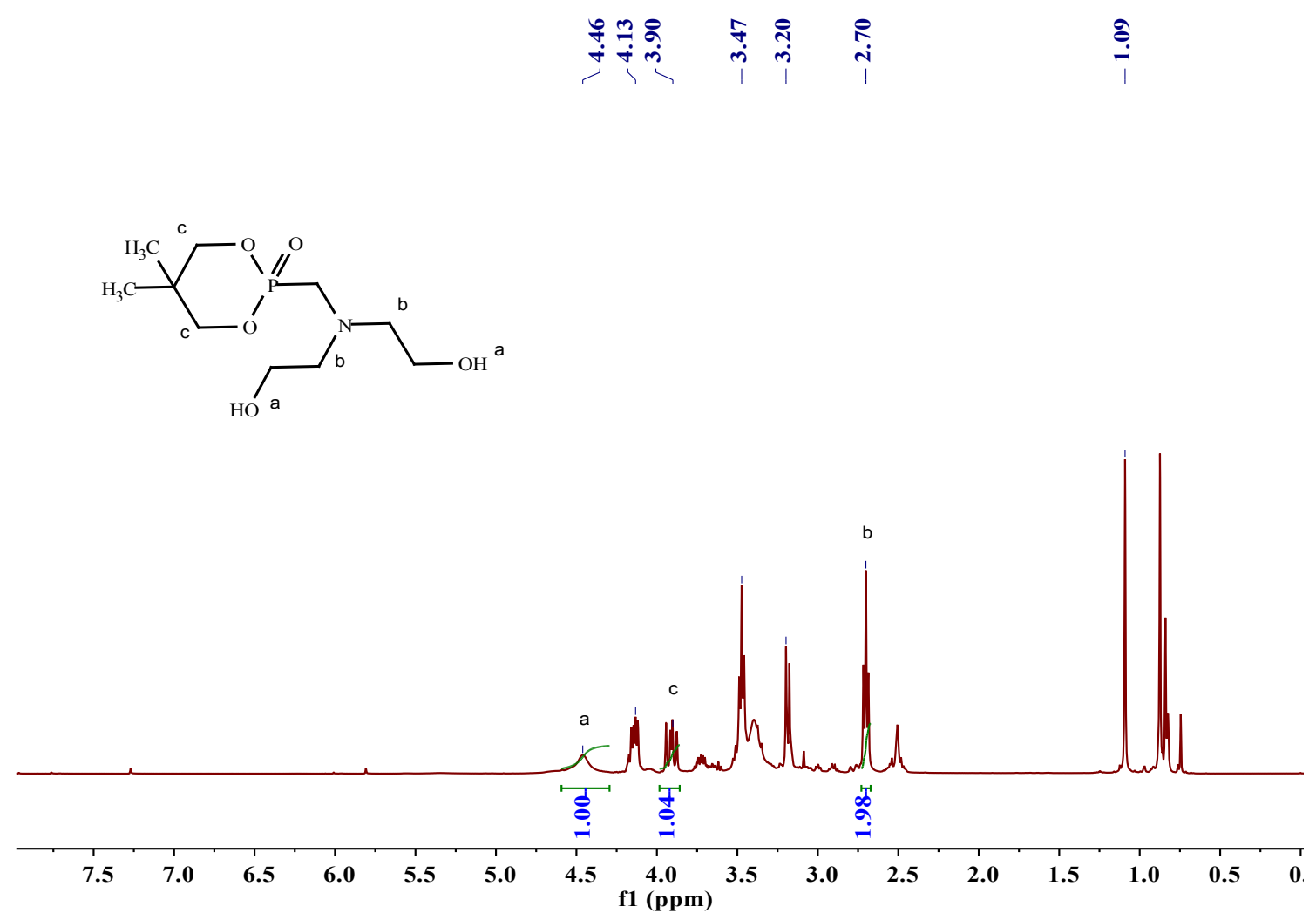

Figure S4. ${ }^{1} \mathrm{H}$ NMR spectra of HAMPP $\left(d_{6}\right.$-DMSO $)$ 


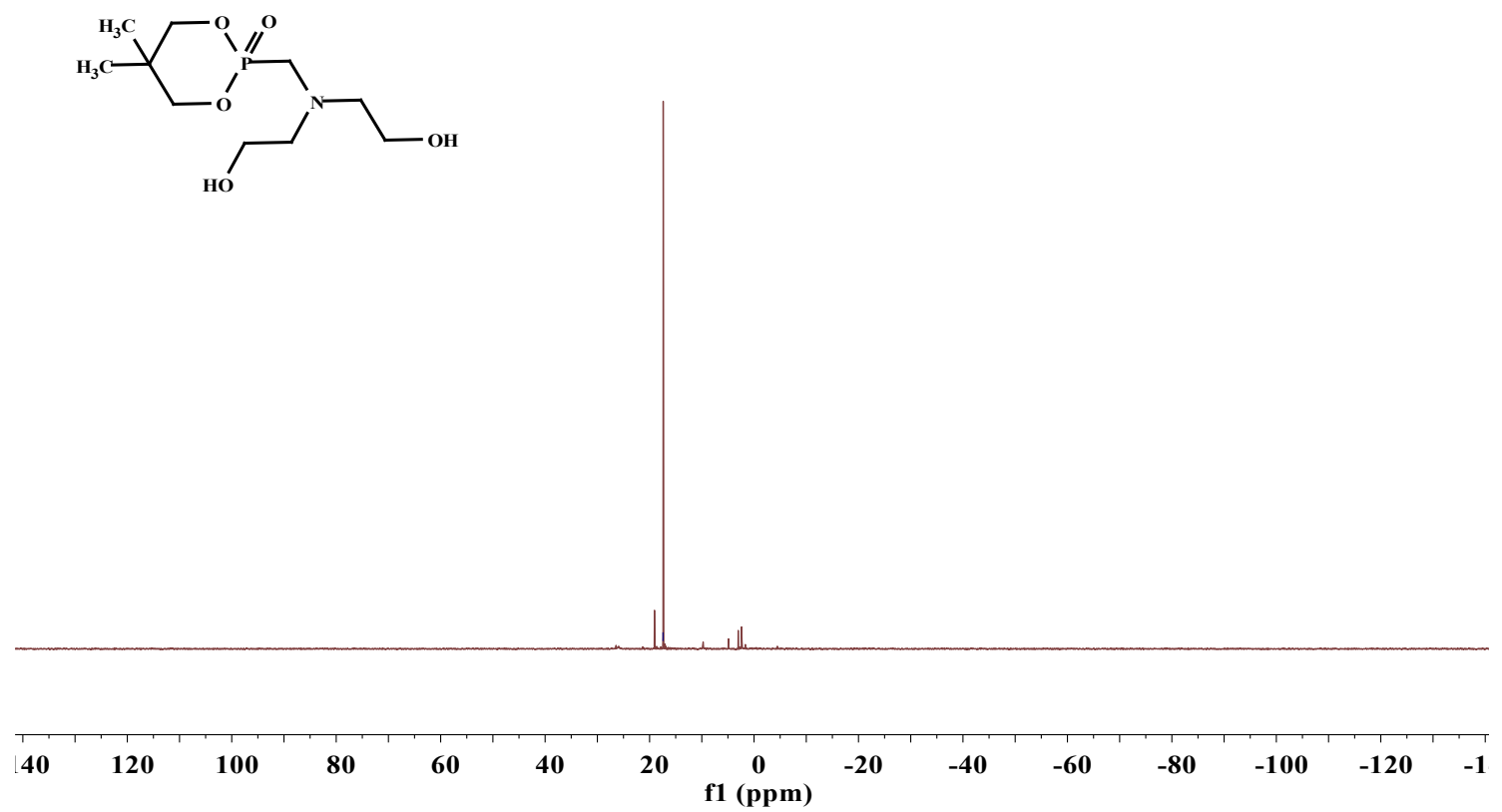

Figure S5. ${ }^{31} \mathrm{P}$ NMR spectra of HAMPP $\left(d_{6}\right.$-DMSO

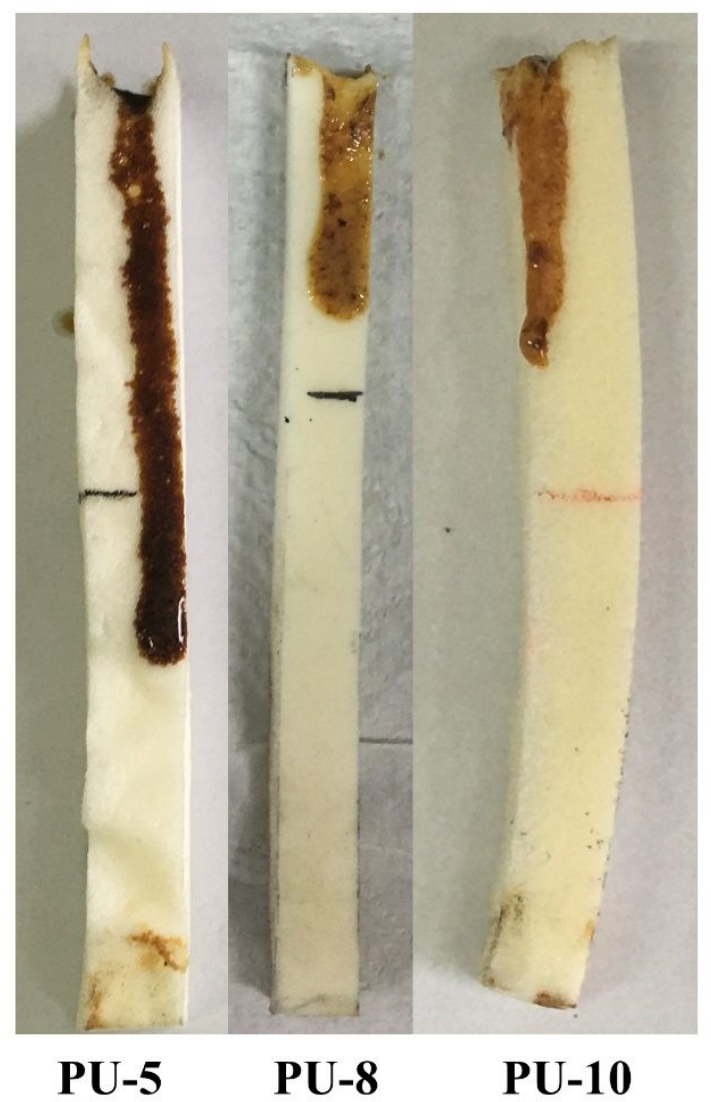

Figure S6. The carbon layer photo of flame-retardant PU foams 


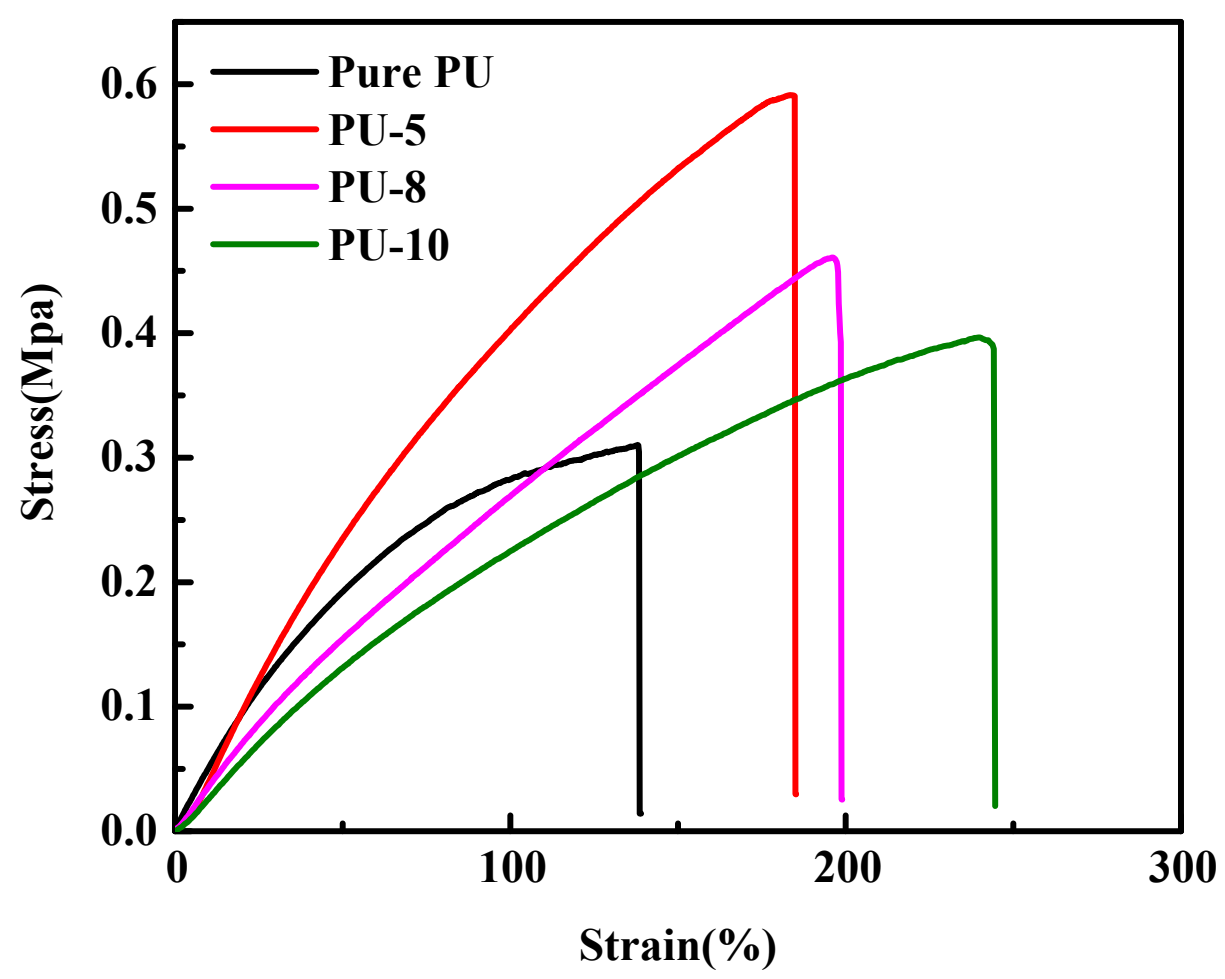

Figure S7. Tensile stress-strain curves of Pure PU and PU-HAMPP hybrids 


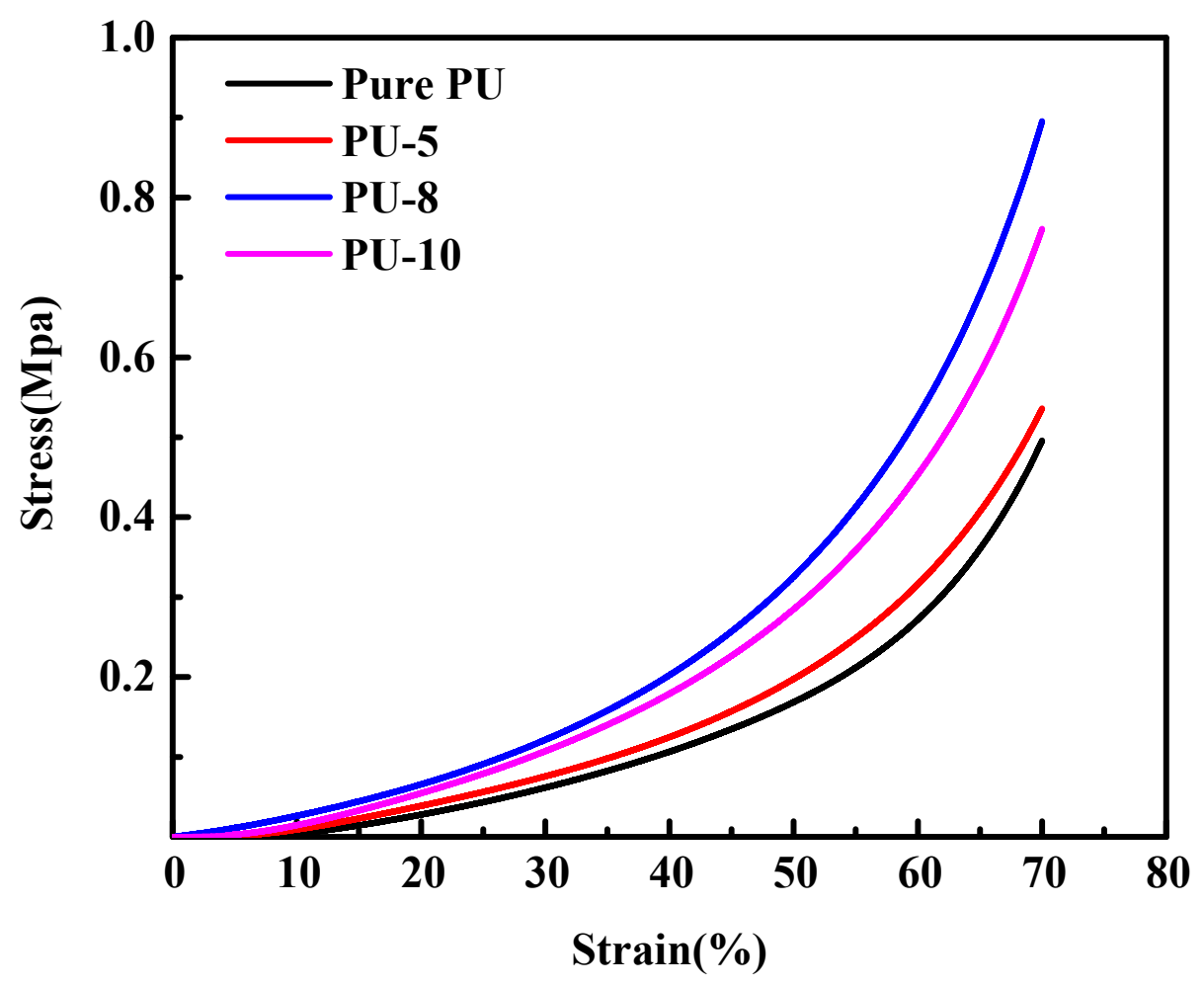

Figure S8. Compressive stress-strain curves of Pure PU and PU-HAMPP hybrids 